\title{
Ambiguous abbreviations: an audit of abbreviations in paediatric note keeping
}

\author{
J E Sheppard, ${ }^{1}$ L C E Weidner, ${ }^{1}$ S Zakai, ${ }^{1}$ S Fountain-Polley, ${ }^{2}$ J Williams'
}

${ }^{1}$ Birmingham Heartlands Hospital, Bordesley Green East, Birmingham, UK; ${ }^{2}$ Birmingham Children's Hospital, Birmingham, UK

Correspondence to: Simon Fountain-Polley, Birmingham Children's Hospital, Birmingham, UK; pollgysim@ yahoo.com

Accepted 30 October 2007 Published Online First

26 November 2007

\section{ABSTRACT}

Objective: To assess the frequency, nature and understanding of abbreviations in medical records.

Design: Audit of abbreviation use and meaning in paediatric handover sheets and medical notes compared to two standards, the Trust Intranet Medical Dictionary (TID) and Mosby's Medical Dictionary (MMD). A selection of abbreviations was shown to healthcare professionals to examine interpretation of abbreviations.

Setting: Large inner-city district general hospital, Birmingham, UK.

Main outcome measures: Frequency, nature and understanding of abbreviations in paediatric medical records.

Results: On 25 handover sheets a total of 2286 abbreviations were used, with 221 different abbreviations; the standards recognised $14 \%$ (TID) and $20 \%$ (MMD) of these abbreviations. In 168 sets of medical notes a total of 3668 abbreviations were used, with 479 different abbreviations; the standards recognised 15\% (TID) and $17 \%$ (MMD). Some words were shortened in different forms, for example, normal (N, NI, NAD) and some abbreviations had multiple interpretations that differed from those intended, for example, TOF (tetralogy of Fallot, tracheo-oesophageal fistula). When presented with a selection of abbreviations, paediatric doctors recognized 56-94\% and other healthcare professionals recognised $31-63 \%$.

Conclusion: Abbreviation use was widespread in paediatric note keeping. There was no systematic approach to this and difficulties in interpretation were demonstrated. The use of standardised abbreviations to avoid confusion is suggested.

Clinicians are accountable for the legibility and accuracy of written patient information. The National Health Service indemnity scheme, the Clinical Negligence Scheme for Trusts ${ }^{1}$ bases its premiums on individual Trusts' risk-management and patient-safety systems. One of the standards against which a Trust is assessed is the quality of its health records.

In the United Kingdom, the European Working Time Directive ${ }^{2}$ is leading to the introduction of full shift systems for junior doctors. Patient information is shared through the use of handover systems and documentation in medical notes. In the paediatric department at The Heart of England NHS Foundation Trust, the team produce a paper handover sheet at every shift change (three times in 24 hours) to transfer information from shift to shift. The written handover sheet is accompanied by a verbal handover. Concerns were raised regarding abbreviation use on these sheets and in the medical notes. An audit was undertaken to investigate the frequency, nature and use of abbreviations in these documents.

\section{METHOD}

An abbreviation was defined as any shortened form of a word, for example "obs" (observation); any acronym, for example "SALT" (speech and language therapy); any contracture, for example "S bifida" (Spina bifida), and any initialism, for example "NGT" (nasogastric tube). Abbreviations were compared with two standards to see whether they were recognised and if alternative meanings existed. The standards used were the medical dictionary available on the Trust intranet (TID) ${ }^{3}$ and Mosby's Medical dictionary (MMD) ${ }^{4}$ used by the paediatric secretaries. One handover sheet was studied in detail to look at the frequency of abbreviation use.

\section{Audit of handover sheets}

A sample of 25 of the 105 handover lists created during the period 8 December 2005 to 11 January 2006 was retained for analysis. The sheets retained were those created at handovers attended by at least one of the authors, therefore ensuring the intended meaning of abbreviations was understood (the authors were not responsible for updating the handover sheets). The sheets assessed included 16 morning, seven afternoon and two evening handover lists; the majority were collected on a weekday (23) with two collected at the weekend. The abbreviations used and their intended interpretations were recorded in a database.

\section{Audit of medical notes}

During the period 12 June 2006 to 23 July 2006, four sets of paediatric unit assessment clerking notes from each day (both weekends and weekdays) were selected from the admissions book by taking the first and last name on the page (the book follows on continuously). A total of 168 sets of records were analysed. This included records of children seen by the paediatric, surgical and trauma and orthopaedic teams. The initial assessment in the paediatric profile was used for data collection, to the point where a definitive management decision (ie, admit or discharge) was made. Each abbreviation, its frequency of use in each set of notes and the professional group and grade of person using the abbreviation was recorded. These details were compiled in a database. The abbreviations were compared to the dictionary standards to identify whether they were recognised abbreviations and if they had alternative meanings to that intended. 


\section{Interpretation of abbreviations}

A selection of abbreviations was shown to members of nonpaediatric specialties who have contact with children and to members of the paediatric department to elucidate abbreviation understanding. The group consisted of nine healthcare professionals; a trauma and orthopaedic senior house officer, an adult medical registrar, a surgical registrar, an ear, nose and throat consultant, a paediatric foundation year 1 doctor, a paediatric senior house officer, a paediatric registrar, a paediatric consultant and paediatric staff grade nurse.

\section{RESULTS}

\section{Results of handover sheets}

The total number of abbreviations in the whole sample was 2286, with an average of 91 abbreviations per handover sheet, with a mean of 32.12 patients per handover sheet (range 22-40). The number of different abbreviations used was 221. Comparison with the TID and Mosby's Medical Dictionary revealed that only a small proportion of the abbreviations used were recognised by these standards (14\% and $20 \%$ respectively), see table 1.

These sources gave alternative meanings for abbreviations from those that were intended on the handover sheet, for example, CCU (intended as coronary care unit) could be critical care unit, CP (intended as cerebral palsy) could be cleft palate, and RR (intended as respiratory rate) could be recovery room. $\mathrm{HB}$, meant as headbox, could be interpreted as haemoglobin. Mosby's Medical Dictionary gave multiple alternative meanings for $4 \%$ of the abbreviations; for example, ED (intended as eating and drinking) could be emergency department or effective dose, and $\mathrm{P}$ (intended as paracetamol) could be pupil, pulse or phosphorus. L was supposed to signify left, but could mean length, lumbar, lethal or pound.

On one single handover sheet covering 32 patients, 58 different abbreviations were found; some were used multiple times, giving a total of 84 abbreviations. Some words were abbreviated in different forms on the same sheet, for example, normal was written as NAD, N and NL; antibiotic was written as $A B X$ and abs; nasogastric feeding was written as NG and NGT. Some abbreviations were given different meanings in different cases; for example, CLD could be congenital or chronic lung disease; TOF could be tetralogy of Fallot or tracheooesophageal fistula.

\section{Results of medical notes}

The total number of abbreviations in the sample was 3668, with an average of 21 abbreviations per set of medical notes. The number of different abbreviations used was 479. Comparison with the TID and Mosby's Medical Dictionary revealed that only a small proportion of the abbreviations used was recognised (15\% and $17 \%$ respectively), see table 2 .

Table 1 Comparison of abbreviations (from handover sheets) with the two standards; in total, 221 abbreviations

\begin{tabular}{|c|c|c|}
\hline & \multicolumn{2}{|c|}{ Standard used for comparison } \\
\hline & $\begin{array}{l}\text { Trust Intranet } \\
\text { Dictionary }^{3}\end{array}$ & $\begin{array}{l}\text { Mosby's Medical } \\
\text { Dictionary }^{4}\end{array}$ \\
\hline Number recognised by source & $30(14 \%)$ & $45(20 \%)$ \\
\hline Number not recognised by source & $191(86 \%)$ & $176(80 \%)$ \\
\hline Number with alternative meaning & $31(14 \%)$ & $24(11 \%)$ \\
\hline Number with $>2$ alternative meanings & $0(0 \%)$ & $8(4 \%)$ \\
\hline
\end{tabular}

These standards gave some of the abbreviations alternative meanings from those intended in the notes and were similar in nature to those found on the handover sheets. Again the TID and Mosby's Medical Dictionary identified several of the abbreviations as having multiple alternative meanings.

When considering the frequency of abbreviation use by individuals, the senior house officer had the highest usage (2083), followed by the registrar, the foundation year 1 doctor, the staff nurse and the medical student (in descending order, $889,199,104$ and 52 respectively). This may reflect the number of clerkings and contributions to medical records by the respective members of staff.

\section{Interpretation of abbreviations}

When healthcare professionals from clinical departments other than paediatrics were asked to blindly interpret the abbreviations none was able to interpret all correctly. The percentage of correct answers for non-paediatric clinicians varied from $63 \%$ (consultant ear, nose and throat surgeon) to $31 \%$ (senior house officer in trauma and orthopaedics). There were four abbreviations that none of the sample could interpret: CACP (choreoathetoid cerebral palsy), CLD (congenital lung disease), LML (left middle lobe pneumonia) and MCD (meningococcal disease).

When the paediatric team were asked to interpret the abbreviations, none was able to interpret all correctly. The consultant scored highest with $94 \%$ correct answers. The senior house officer scored lowest with $56 \%$, see figure 1 .

\section{DISCUSSION}

This is the first audit of abbreviation use in paediatric documentation in the United Kingdom. With the apparent widespread use of abbreviations on handover sheets and in medical notes there are implications for clinical governance.

\section{Implications of the audit}

Large numbers of abbreviations were used in the paediatric documentation audited. Individuals used abbreviations differently. There were both general medical and paediatric-specific abbreviations. There were examples of several abbreviations used for a single meaning and different meanings given to a single abbreviation. Although abbreviations allow large amounts of information to be conveyed in a small space, this audit demonstrates that most are not recognised by the reference standards. There was poor understanding of the abbreviations by both paediatric staff and other specialist medical staff that used the paediatric documentation.

Concern regarding abbreviation use in the medical records is widespread. ${ }^{56}$ One audit in an Australian tertiary paediatric centre found that communication was hindered by use of abbreviations in progress reports and that overall comprehension of written information was only fair to average.? Another

Table 2 Comparison of abbreviations (from medical records) with the two standards; in total, 479 abbreviations

\begin{tabular}{lcc}
\hline & \multicolumn{2}{l}{ Standard used for comparison } \\
\cline { 2 - 3 } & $\begin{array}{l}\text { Trust Intranet } \\
\text { Dictionary }\end{array}$ & $\begin{array}{l}\text { Mosby's Medical } \\
\text { Dictionary }^{4}\end{array}$ \\
\hline Number recognised by source & $74(15 \%)$ & $82(17 \%)$ \\
Number not recognised by source & $405(85 \%)$ & $397(83 \%)$ \\
Number with alternative meaning & $79(16 \%)$ & $108(23 \%)$ \\
Number with $>2$ alternative meanings & $14(3 \%)$ & $59(12 \%)$ \\
\hline
\end{tabular}




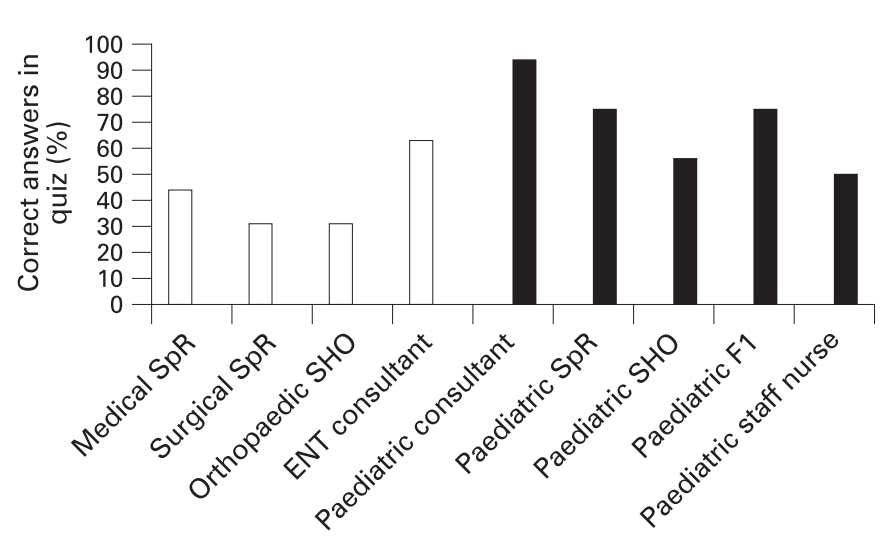

Figure 1 Results of abbreviation understanding quiz.

study of abbreviation use in daily progress reports in a specialcare baby unit concluded that unacceptable abbreviations were being used. ${ }^{8}$ Although none had appeared to result in an erroneous interpretation as most staff were familiar with their use, they concluded that some form of standardisation of abbreviations was required.

There is a paucity of evidence linking misinterpretation of abbreviations to outcome. An American neonatal intensive care unit undertook a study in 2003 that showed that documentation errors were associated with longer length of hospital stay. ${ }^{9}$ They concluded that as medical decision-making relies on available information, inaccurate documentation could potentially contribute to sub-optimal decision-making and outcome.

\section{Strengths and limitations of the handover sheets audit}

Handover sheets were collected over a prolonged period to eliminate user bias. Sheets were only included for analysis if one of the authors had been present at the accompanying verbal handover, so that intended meaning of the abbreviations was known. The selection of handover sheets was not random, but was determined by the shift patterns of the authors.

\section{Strengths and limitations of the medical notes audit}

Medical notes were collected over a prolonged period of time to eliminate user bias. Notes from patients under the care of paediatrics as well as other specialties were used for analysis.

Intended meaning of the abbreviation had to be assumed from the context of the medical notes.

\section{Survey of heath professionals interpretations of abbreviations}

This was intended as a reflection of the extent to which abbreviations were interpreted correctly. The healthcare professionals were asked to interpret the abbreviations out of context. The consultant recognised the most abbreviations, and we surmise that this may be because of wider experience.

\section{CONCLUSION}

Abbreviations have their place in medical record keeping and are an important means of conveying large amounts of information

\section{What is already known on this topic}

- Effective communication is vital for making clinical decisions. Written patient information plays an important part in communication between health professionals, especially with hospitals increasingly adopting shift systems for doctors.

- Concern over use of abbreviations is widespread but little research has been carried out into their use.

\section{What this study adds}

- This study confirms that use of abbreviations is widespread.

- There are difficulties in interpreting abbreviations accurately. Different abbreviations are used for the same word and some abbreviations can have different meanings depending on context; the use of a system of standardised abbreviations to avoid confusion is suggested.

concisely. There is variation in the use and meaning of abbreviations and to prevent misunderstanding only standard abbreviations should be used.

Since conducting the audit, a list of standard abbreviations (available on request) for use in the department has been created using the Mosby's Medical Dictionary, and this list is displayed prominently in the paediatric department and is to be included in the local protocol book. By having a small number of accepted abbreviations with which all clinicians are familiar and by providing reference lists of accepted abbreviations in prominent places, it is hoped that all communication within the written documentation can be understood without sacrificing conciseness. The success of this will require dissemination and promotion by senior clinicians within the department, with the use of audit to measure practice change.

Funding: None.

Competing interests: None.

\section{REFERENCES}

1. Towns D. The role of the NHS Litigation Authority. NHSLA J 2001;1:18-19.

2. Incomes Data Services research organisation. Full text of European Working Time Directive (93/104/EC) http://www.incomesdata.co.uk/information/ worktimedirective.htm (accessed 3 Jan 2008).

3. Online medical dictionary via Trust intranet. Published by the Department of Medical Oncology, University of Newcastle Upon Tyne. http://cancerweb.ncl.ac.uk/ omd/ (accessed 3 Jan 2008).

4. Anderson DM. Mosby's medical, nursing and allied health dictionary. $6^{\text {th }}$ edn. UK version. CV Mosby, London: 2002.

5. Goodman N. Abbreviations in journals. Lancet 1994;343:8910.

6. Cheng T. Abbreviations in journals. Lancet 1994;343:8910.

7. Dawson KP, Capaldi N, Haydon M, et al. The paediatric hospital medical record: a quality assessment. Aust Clin Rev 1992;12:89-93.

8. Manzar S, Nair AK, Govind Pai M, et al. Use of abbreviations in daily progress notes. Arch Dis Child Fetal Neonatal Ed 2004;89:F374.

9. Carroll AE, Tarczy-Hornoch P, O'Reilly E, et al. Resident documentation discrepancies in a neonatal tntensive care unit. Pediatrics 2003;111(5):976-80. 